\title{
Healthcare Utilization and Costs During the Initial Phase of Care Among Elderly Women With Breast Cancer
}

\author{
Ami Vyas, PhDª ; S. Suresh Madhavan, PhD, MBA ${ }^{\text {; }}$ Usha Sambamoorthi, PhD ${ }^{\text {b }}$ Xiaoyun (Lucy) Pan, PhDc; \\ Michael Regier, $\mathrm{PhD}^{\mathrm{d}}$; Hannah Hazard, MD; ; and Sita Kalidindi, MS
}

\begin{abstract}
Background: Understanding the patterns of healthcare utilization and costs during the initial phase of care (12 months after breast cancer $[B C]$ diagnosis) in older women (aged $\geq 65$ years) is crucial in the allocation of Medicare resources. The objective of this study was to determine healthcare utilization and costs during the initial phase of care in older, female, Medicare fee-for-service beneficiaries diagnosed with BC, and to determine the factors associated with higher costs. Methods: A retrospective observational study using the SEER-Medicare linked database was conducted in 69,307 women aged $\geq 66$ years diagnosed with primary incident BC in 2003-2009 to determine healthcare utilization, average costs, and costs for specific services during the initial phase of care. Generalized linear model regression was conducted to identify the factors associated with higher costs in a multivariate framework. Results: A total of $96 \%$ of women were treated with surgery during the initial phase of BC care, whereas $21 \%$ and $54 \%$ underwent chemotherapy and radiotherapy, respectively. Costs during the initial phase of care totalled $\$ 28,075$ in 2012 USD, comprising \$13,344 for physician services and \$7,456 for outpatient services. Factors associated with higher costs during the initial phase of care were younger age (66-69 years), African American race, higher household income, advanced stages of BC, initial BC treatment, higher number of primary care physician visits, and presence of comorbidities and/or a mental condition. Conclusions: The economic burden of BC is substantial during the initial phase of care. Physician and outpatient services accounted for the highest proportion of costs. Predisposing factors, need-related factors, healthcare use, and external environmental healthcare factors significantly predicted costs during the initial phase of care.
\end{abstract}

J Natl Compr Canc Netw 2017;15(11):1401-1409 doi: 10.6004/jncen.2017.0167

Due to scientific advances in oncology, increased use of more expensive cancer treatments, and an aging population, the cost of cancer care is expected to increase enormously. In 2010, the national cost of cancer care was estimated to be $\$ 124.6$ billion USD in the SEER-Medicare

\footnotetext{
From the aDepartment of Pharmacy Practice, College of Pharmacy, University of Rhode Island, Kingston, Rhode Island; 'bepartment of Pharmaceutical Systems and Policy, School of Pharmacy, West Virginia University, Morgantown, West Virginia; 'Sunovion Pharmaceuticals, Marlborough, Massachusetts; dDepartment of Biostatistics, School of Public Health, West Virginia University, Morgantown, West Virginia; and eDepartment of Surgery, School of Medicine, Mary Babb Randolph Cancer Center, West Virginia University, Morgantown, West Virginia. Submitted February 24, 2017; accepted for publication June 6, 2017. The authors have disclosed that they have no financial interests, arrangements, affiliations, or commercial interests with the manufacturers of any products discussed in this article or their competitors.

This study was part of Dr. Vyas' doctoral dissertation at West Virginia University and was supported by an AHRQ grant (R24HS018622-03). Some additional salary support was received by Drs. Madhavan and Sambamoorthi from a National Institute of General Medicine Sciences
}

population, of which female breast cancer (BC) constituted the highest proportion at $13 \%$ ( $\$ 16.5$ billion). Further, it is projected to increase by $32 \%$ in 2020 , presenting a significant burden to Medicare. ${ }^{1}$ Of the $\$ 16.5$ billion, the initial phase of care (12 months) following BC diagnosis

(NIGMS) IDeA Clinical and Translational Research grant (U54GM104942) obtained by West Virginia University. The content is solely the responsibility of the authors and does not necessarily represent the official views of AHRQ and NIGMS.

Partial results of this analyses were presented at the International Society for Pharmacoeconomics and Outcomes Research 20th Annual International Meeting; Philadelphia, PA; May 16-20, 2015.

Author contributions: Study concept and design: Vyas, Madhavan, Sambamoorthi, Pan, Regier, Hazard. Data acquisition: Vyas, Madhavan, Sambamoorthi, Kalidindi. Data analysis: Vyas, Madhavan, Sambamoorthi, Kalidindi. Data interpretation: All authors. Manuscript preparation: All authors. Final approval: All authors.

Correspondence: Ami Vyas, PhD, University of Rhode Island, College of Pharmacy, Department of Pharmacy Practice, 7 Greenhouse Road, Kingston, RI 02881. E-mail: avyas@uri.edu 
Vyas et al

represented $37 \%$ of the cost, the continuing phase of care $41 \%$, and the last year of life accounted for $22 \%$. $\mathrm{BC}$ costs are substantially higher for the initial phase of care due to surgery, radiotherapy (RT), and adjuvant therapy. ${ }^{2-6}$ Regardless of these extensive costs to Medicare, there is insufficient up-to-date information on healthcare utilization and costs incurred by specific services, and factors significantly contributing to these costs in women aged $\geq 65$ years. Because older women have higher $\mathrm{BC}$ incidence than their younger counterparts, ${ }^{7}$ it is important to determine the economic burden of $\mathrm{BC}$ in planning for future healthcare resource allocation.

A descriptive review about the costs of cancer care in the United States reported that studies varied widely regarding settings, methodologies, cost perspectives, populations, measurements of costs, types of services included, time horizons, and data sources. ${ }^{8}$ Another systematic review included outdated studies, which may not reflect changes in the patterns of care due to technological advances and innovations in BC treatment. ${ }^{3}$ Furthermore, other studies used data from fewer cancer registries, and not for all $\mathrm{BC}$ stages. ${ }^{1,2,6,9,10}$ Additionally, costs according to types of specific services have not been reported. ${ }^{6,10}$ One study that determined costs during the initial phase of care for Medicare beneficiaries with BC in Virginia reported comorbidity, hospital stay, and type of treatment as the significant cost contributors. ${ }^{11}$ Another study that used SEER-Medicare data reported higher healthcare utilization, although the study findings had limited generalizability due to inclusion of only 4 SEER geographic areas. ${ }^{9}$ In fact, to date, no single comprehensive study focusing on both healthcare utilization and costs during the initial phase of care in older women with BC from all SEER areas has been published with the results stratified by specific services.

The purpose of this study was to determine the treatment approaches and healthcare utilization and costs during the initial phase of $\mathrm{BC}$ care among female Medicare fee-for-service beneficiaries using the SEER-Medicare data, and to determine factors associated with costs using a multivariate framework.

\section{Methods}

\section{Study Design and Data Source}

A retrospective observational cohort study was conducted from the Medicare perspective using data from the SEER program, which routinely gathers data on socioeconomic and clinical factors about cancer cases from 17 population-based tumor registries that in turn collect data from hospitals, outpatient clinics, laboratories, private practitioners, hospices, autopsy reports, and death certificates; it represents $26 \%$ of the US population. ${ }^{12}$ Approximately $94 \%$ of SEER cases were matched to their Medicare claims from the time of their eligibility until death based on name, social security number, sex, and date of birth. ${ }^{13}$ This study used information from the Medicare claims files, which were linked to the SEER cancer cases. ${ }^{14}$ More details of the SEER-Medicare data set are described elsewhere. ${ }^{12}$ For this study, the Area Resource File was linked to the SEER-Medicare data set using the state and county Federal Information Processing Standards code for each beneficiary in order to obtain the county level information on income, education, healthcare providers, and hospitals offering oncology services. ${ }^{15}$

\section{Study Cohort}

The study cohort comprised women aged $\geq 66$ years with first primary incident BC (ICD-9-CM codes 174.xx, 233.0x, 238.3x, 239.3x) during 2003-2009. Among a total of 195,067 women identified, the following women were excluded: 11,031 who died within 12 months after BC diagnosis; 71,254 aged $<66$ years; 5,524 with any previous cancer diagnosis; 5 who were diagnosed with $\mathrm{BC}$ during death or autopsy; 2,072 with unknown or missing BC stage; 6,299 not continuously enrolled in Medicare Parts $A$ and $B$ in the 12 months before and after diagnosis; 29,195 who were members of a health maintenance organization at any time during the study period; and 380 who had zero Medicare costs. Therefore, 69,307 women met inclusion criteria.

\section{Measures}

Initial Phase of Care: Based on the consensus from a group of clinical oncologists, the initial phase of care was defined as 12 months after BC diagnosis; initial courses of treatment including adjuvant therapy were usually completed within 1 year of cancer diagnosis; this definition is used for comparison purposes with previous literature. ${ }^{1,2,4-6,11,16}$

Healthcare Utilization: Healthcare utilization included inpatient visits, hospitalization days, outpa- 
tient visits, and emergency department (ED) visits derived from Medicare claims files. Additionally, the percentage of women who received surgery, RT, or chemotherapy was calculated. The average number of RT and chemotherapy visits were determined.

Cost Estimates: All of the Medicare files, including inpatient (Medicare Provider Analysis and Review [MedPAR]), hospital outpatient, carrier/National Claims History $(\mathrm{NCH})$, hospice, home health agency (HHA), and durable medical equipment (DME) files, were used to obtain direct Medicare costs. Costs were defined as the amount reimbursed by Medicare. Reimbursement, used as a proxy for Medicare costs in previous cost studies, ${ }^{4,5,10}$ are actual payments derived from reimbursement formulas reflecting the average resource utilization for each healthcare service. ${ }^{17}$ Total costs, costs within the categories of care, such as inpatient services obtained from MedPAR file, outpatient services obtained from outpatient file, physician services obtained from NCH file, and other services (DME, hospice care, and HHA), were calculated to identify which Medicare component contributed substantially to total costs. All costs were adjusted using the previously used $\operatorname{method}^{6}$ and were reported in 2012 \$USD to account for variation over time. ${ }^{18}$

Independent Variables: To identify the factors associated with costs, the Andersen behavioral model of healthcare services utilization was used. ${ }^{19,20}$ According to this model, use of healthcare services is a function of people's predisposition to use services, factors that enable or impede use, need for care, and factors associated with healthcare use and external environmental healthcare-related factors. Predisposing factors included age at BC diagnosis and race; whereas enabling factors included marital status, census tract median household income, and census tract percentage of people aged $\geq 25$ years with at least 4 years of college education. Need-related factors related to specific cancer care included stage at diagnosis, ${ }^{21}$ grade of tumor, estrogen receptor (ER) status, comorbidity score, ${ }^{22,23}$ and mental health conditions (ie, depression and/or anxiety) derived from co-occurring chronic conditions within 12 months before BC diagnosis. Factors associated with healthcare use were the number of primary care physician (PCP) visits in the year prior to $\mathrm{BC}$ diagnosis, ${ }^{24}$ type of initial treatment in the year of $\mathrm{BC}$ diagnosis (ie, definitive surgery only, nonsurgical treatment [chemotherapy, RT, or both], definitive surgery plus nonsurgical treatment, no treatment), and inpatient use. External environmental healthcare-related factors included location of residence, SEER region, and number of hospitals offering oncology-related services in the area of residence.

\section{Statistical Analyses}

Descriptive statistics were used to describe the characteristics of the study cohort. Average healthcare utilization was calculated for each service, as well as for RT and chemotherapy. Percentages were determined of women who had surgery, chemotherapy, or RT, and those who had at least one inpatient, outpatient, or ED visit. To understand the trends in costs over time, average total costs and costs according to specific services during the initial phase of $\mathrm{BC}$ care were calculated and reported for each calendar year of diagnosis.

The Breusch-Pagan/Cook-Weisberg test and simplified White test were performed to report the heteroscedasticity and kurtosis of log-scale residuals in the cost data. ${ }^{25}$ Due to distributional problems of cost data, Park tests ${ }^{26}$ were conducted to determine the most appropriate regression model for data based on which generalized linear model (GLM) with log link function and gamma distribution was conducted to model costs and identify its predictors in a multivariate framework. From the regression, the regression estimates (betas) were exponentiated to yield average costs. The findings with $P$ values $\leq 0.05 \mathrm{lev}$ els are discussed. All analyses were conducted using SAS version 9.4 (SAS Institute Inc., Cary, NC) and Stata version 13 (StataCorp LP, College Station, TX).

\section{Results}

\section{Descriptive}

Table 1 describes the study cohort along with the average costs during the initial phase of care within each group. Most patients were white $(88 \%)$, resided in metropolitan areas (84\%), were diagnosed with local-stage BC (58\%), had ER-positive status (72\%), and had no mental condition (94\%) or comorbidity $(57 \%)$. Average costs were higher among women who were black; resided in metropolitan areas; were diagnosed with distant, poorly differentiated, and 
Vyas et al

\begin{tabular}{|c|c|c|c|c|}
\hline Variables & $\mathrm{n}$ & $\%$ & Average Costs (SUSD) & SD \\
\hline \multicolumn{5}{|l|}{ Age at diagnosis, y } \\
\hline $66-69$ & 15,789 & 22.8 & $\$ 31,656$ & $\$ 25,398$ \\
\hline 70-74 & 17,605 & 25.4 & $\$ 29,971$ & $\$ 24,847$ \\
\hline 75-79 & 15,901 & 22.9 & $\$ 27,582$ & $\$ 23,117$ \\
\hline$\geq 80$ & 20,012 & 28.9 & $\$ 23,975$ & $\$ 22,006$ \\
\hline \multicolumn{5}{|l|}{ Race } \\
\hline White & 61,122 & 88.2 & $\$ 27,848$ & $\$ 23,341$ \\
\hline Black & 5,043 & 7.3 & $\$ 31,778$ & $\$ 29,386$ \\
\hline Other & 3,142 & 4.5 & $\$ 26,567$ & $\$ 25,945$ \\
\hline \multicolumn{5}{|l|}{ Location of residence } \\
\hline Metropolitan & 57,894 & 83.5 & $\$ 28,648$ & $\$ 24,317$ \\
\hline Nonmetropolitan & 11,413 & 16.5 & $\$ 25,170$ & $\$ 21,949$ \\
\hline \multicolumn{5}{|l|}{ Marital status } \\
\hline Married/Partnered & 30,502 & 44.0 & $\$ 28,239$ & $\$ 22,573$ \\
\hline Single/Divorced/Widowed & 38,805 & 56.0 & $\$ 27,947$ & $\$ 25,026$ \\
\hline \multicolumn{5}{|l|}{ Census tract income } \\
\hline$\leq \$ 25,000$ & 4,712 & 6.8 & $\$ 28,439$ & $\$ 25,927$ \\
\hline$\$ 25,001-\$ 50,000$ & 33,856 & 48.8 & $\$ 27,547$ & $\$ 24,115$ \\
\hline$\$ 50,001-\$ 75,000$ & 20,654 & 29.8 & $\$ 28,530$ & $\$ 23,716$ \\
\hline$>\$ 75,000$ & 10,085 & 14.6 & $\$ 28,747$ & $\$ 23,046$ \\
\hline \multicolumn{5}{|l|}{ Census tract education } \\
\hline $0-13.33$ & 17,341 & 25.0 & $\$ 28,388$ & $\$ 25,244$ \\
\hline $13.34-22.98$ & 17,339 & 25.0 & $\$ 27,916$ & $\$ 24,280$ \\
\hline $22.99-38.79$ & 17,301 & 25.0 & $\$ 28,125$ & $\$ 23,957$ \\
\hline$\geq 38.80$ & 17,326 & 25.0 & $\$ 27,873$ & $\$ 22,335$ \\
\hline \multicolumn{5}{|l|}{ Stage at diagnosis } \\
\hline In situ & 11,727 & 16.9 & $\$ 18,354$ & $\$ 16,518$ \\
\hline Localized & 40,125 & 57.9 & $\$ 25,085$ & $\$ 19,900$ \\
\hline Regional & 15,349 & 22.2 & $\$ 40,014$ & $\$ 28,478$ \\
\hline Distant & 2,106 & 3.0 & $\$ 52,182$ & $\$ 40,381$ \\
\hline \multicolumn{5}{|l|}{ Tumor grade } \\
\hline Well-differentiated & 15,151 & 21.8 & $\$ 23,711$ & $\$ 18,213$ \\
\hline Moderately differentiated & 27,841 & 40.2 & $\$ 27,488$ & $\$ 22,873$ \\
\hline Poorly differentiated & 17,463 & 25.2 & $\$ 34,276$ & $\$ 28,031$ \\
\hline Undifferentiated/Unknown & 8,852 & 12.8 & $\$ 25,160$ & $\$ 24,906$ \\
\hline
\end{tabular}

Abbreviation: SD, standard deviation.

(continued on next page)

ER-negative tumors; had $\geq 2$ comorbidities and reported any mental condition; and received nonsurgical treatment only during the initial phase.

\section{Healthcare Utilization}

The upper part of Table 2 describes healthcare utilization wherein surgical intervention was reported for $96 \%$ of women. The mean number of chemotherapy visits was 2.5 (SD, 6.9), and $21 \%$ of the study cohort used this treatment at least once during the initial phase of care. The mean number of RT visits was 6.2 (SD, 8.0), and 54\% used RT. Almost all patients $(99.9 \%)$ reported at least one outpatient visit, with an average of 40.1 visits (SD, 20.3); $45 \%$ of the cohort reported at least one inpatient visit, with an average of 0.7 visits $(\mathrm{SD}, 1.1)$ and an average of 4.7 hospitalization days (SD, 14.8). Almost a quarter of the cohort (24\%) reported $\geq 1$ ED visit with an average of 0.4 visits $(\mathrm{SD}, 1.0)$.

\section{Average Costs and Associated Trends}

The lower part of Table 2 describes average costs and costs by types of specific services. Average costs were $\$ 28,075$ (SD, \$23,978). Physician services contributed to the highest proportion $(47.5 \%)$ of the costs $(\$ 13,344 ; \mathrm{SD}, \$ 13,773)$, whereas inpatient and outpatient services contributed to $21.5 \%$ and $26.6 \%$ of the costs, respectively, with corresponding amounts of $\$ 6,046$ (SD, $\$ 13,905)$ and $\$ 7,456$ (SD, \$8,593), respectively.

Figure 1 describes trends in the average total costs and costs by types of specific services. From 2003 through 2009, there was an increase in average total costs (from $\$ 26,361$ to $\$ 29,522$, respectively), average costs due to outpatient services (from $\$ 6,447$ to $\$ 8,730$, respectively), and average costs due to physician services (from $\$ 12,032$ to $\$ 13,946$, respectively), whereas the average costs due to inpatient services declined (from $\$ 6,620$ to $\$ 5,602$, respectively). 
Healthcare Utilization and Costs in Breast Cancer

\begin{tabular}{|c|c|c|c|c|}
\hline Variables & $\mathbf{n}$ & $\%$ & Average Costs (\$USD) & SD \\
\hline \multicolumn{5}{|l|}{ Estrogen receptor status } \\
\hline Positive & 50,136 & 72.3 & $\$ 27,327$ & $\$ 22,303$ \\
\hline Negative & 9,634 & 13.9 & $\$ 36,781$ & $\$ 29,296$ \\
\hline Borderline/Unknown & 9,537 & 13.8 & $\$ 23,214$ & $\$ 24,354$ \\
\hline \multicolumn{5}{|l|}{ Initial treatment } \\
\hline Surgery only & 24,812 & 35.8 & $\$ 18,383$ & $\$ 19,844$ \\
\hline Surgery + adjuvant therapy & 41,925 & 60.5 & $\$ 33,901$ & $\$ 23,588$ \\
\hline Nonsurgical treatment & 1,015 & 1.5 & $\$ 41,245$ & $\$ 36,653$ \\
\hline No treatment & 1,555 & 2.2 & $\$ 17,053$ & $\$ 28,575$ \\
\hline \multicolumn{5}{|l|}{ Inpatient use } \\
\hline Yes & 30,867 & 44.5 & $\$ 37,198$ & $\$ 29,290$ \\
\hline No & 38,440 & 55.5 & $\$ 20,750$ & $\$ 15,075$ \\
\hline \multicolumn{5}{|l|}{ Comorbidity } \\
\hline 0 & 39,279 & 56.7 & $\$ 26,414$ & $\$ 21,950$ \\
\hline 1 & 18,755 & 27.1 & $\$ 28,513$ & $\$ 24,336$ \\
\hline$\geq 2$ & 11,273 & 16.2 & $\$ 33,137$ & $\$ 28,900$ \\
\hline \multicolumn{5}{|l|}{ Mental condition } \\
\hline Yes & 4,412 & 6.4 & $\$ 31,611$ & $\$ 27,499$ \\
\hline No & 64,895 & 93.6 & $\$ 27,835$ & $\$ 23,701$ \\
\hline \multicolumn{5}{|l|}{ Primary care physician visits } \\
\hline $0-1$ & 16,017 & 23.1 & $\$ 27,592$ & $\$ 24,473$ \\
\hline $2-4$ & 21,771 & 31.4 & $\$ 26,757$ & $\$ 22,386$ \\
\hline $5-7$ & 15,302 & 22.1 & $\$ 27,483$ & $\$ 22,686$ \\
\hline$\geq 8$ & 16,217 & 23.4 & $\$ 30,882$ & $\$ 26,392$ \\
\hline \multicolumn{5}{|c|}{ Hospitals offering oncology services } \\
\hline $0-1$ & 21,007 & 30.1 & $\$ 26,149$ & $\$ 22,206$ \\
\hline $2-3$ & 17,755 & 25.5 & $\$ 27,883$ & $\$ 23,090$ \\
\hline $4-6$ & 11,521 & 16.5 & $\$ 28,990$ & $\$ 24,455$ \\
\hline$\geq 7$ & 19,404 & 27.8 & $\$ 29,809$ & $\$ 26,103$ \\
\hline \multicolumn{5}{|l|}{ SEER region } \\
\hline Northeast & 14,620 & 21.1 & $\$ 30,196$ & $\$ 24,676$ \\
\hline South & 17,316 & 25.0 & $\$ 26,340$ & $\$ 22,852$ \\
\hline North Central & 8,705 & 12.6 & $\$ 27,283$ & $\$ 22,786$ \\
\hline West & 28,666 & 41.3 & $\$ 28,283$ & $\$ 24,537$ \\
\hline
\end{tabular}

Abbreviation: SD, standard deviation.

Costs were higher in the study cohort with advanced-stage versus early-stage $\mathrm{BC}$ : $\$ 18,354$ among those with in situ BC; $\$ 25,085$ for those with localstage $\mathrm{BC} ; \$ 40,014$ for those with regional-stage $\mathrm{BC}$; and $\$ 52,182$ for those with distant-stage BC (data not shown). Moreover, costs for specific services (inpatient and outpatient services, physician services, and other services) increased with advancing stage at diagnosis.

\section{Factors Associated With Average Costs}

Table 3 summarizes results from the GLM regression on costs. Women who were diagnosed at advanced stages of BC, did not have a well-differentiated tumor grade, had ER-negative tumor status, had treatment in the form of surgery or adjuvant therapy, reported inpatient use, had higher PCP visits, and had any comorbidity and/or mental condition had significantly higher costs during the initial phase. Women who were black, resided in areas with at least 4 hospitals offering oncology services, lived in the Northeast SEER region, and lived in areas where the household income was $\geq \$ 50,000$ had higher costs as well. In addition, women who were aged $\geq 70$ years, were of "other" race, were married/partnered, and resided in nonmetropolitan areas and in the South and North Central SEER regions had significantly lower costs during the initial phase of care.

\section{Discussion}

As costs of $\mathrm{BC}$ treatment constitute a substantial portion of overall national cancer costs and are projected to increase tremendously in the coming years, ${ }^{1}$ estimating average costs and costs by types of specific services is critical for Medicare to identify cost drivers. This study is the first of its kind to use more recent SEER-Medicare data from 2003-2009 $\mathrm{BC}$ cases to estimate healthcare utilization, average costs, costs by types of specific services, and the sig- 
Vyas et al

\begin{tabular}{|c|c|}
\hline Variables & $\begin{array}{c}\text { \% of Patients } \\
(\mathrm{N}=69,307)\end{array}$ \\
\hline \multicolumn{2}{|l|}{ Treatment } \\
\hline Surgery \pm adjuvant therapy & 96.3 \\
\hline Chemotherapy \pm surgery & 20.8 \\
\hline Radiation therapy \pm surgery & 54.4 \\
\hline \multicolumn{2}{|l|}{ Other healthcare use } \\
\hline Inpatient visits & 44.5 \\
\hline Outpatient visits & 99.9 \\
\hline \multirow[t]{2}{*}{ Emergency visits } & 23.7 \\
\hline & Average Visits (SD) \\
\hline \multicolumn{2}{|l|}{ Treatment } \\
\hline Chemotherapy visits & $2.5(6.9)$ \\
\hline Radiation therapy visits & $6.2(8.0)$ \\
\hline \multicolumn{2}{|l|}{ Other healthcare use } \\
\hline Inpatient visits & $0.7(1.1)$ \\
\hline Hospitalization days & $4.7(14.8)$ \\
\hline Outpatient visits & $40.1(20.3)$ \\
\hline \multirow[t]{2}{*}{ Emergency visits } & $0.4(1.0)$ \\
\hline & Average Costs (SD) \\
\hline Total costs & $\$ 28,075(\$ 23,978)$ \\
\hline Inpatient costs & $\$ 6,046(\$ 13,905)$ \\
\hline Outpatient costs & $\$ 7,456(\$ 8,593)$ \\
\hline Physician services costs & $\$ 13,344(\$ 13,773)$ \\
\hline Other costs (HHA, HSP, DME) & $\$ 1,230(\$ 3,876)$ \\
\hline
\end{tabular}

Abbreviations: DME, durable medical equipment; $\mathrm{HHA}$, home health agency; HSP, hospice.

nificant predictors of costs during the initial phase of care.

The percentage of women who underwent surgery during the initial phase of care was significantly higher than that reported in a previous study $(96 \%$ vs $91 \%)$, whereas the percentages who underwent chemotherapy, RT, and hospitalization remained nearly consistent with the previously published data (21\%, 54\%, and 45\%, respectively). ${ }^{10}$ The average cost during the initial phase of care in older women with incident BC was $\$ 28,075$, which is significantly higher than the costs reported in previous studies. ${ }^{6,9,11}$ Before and during our study period, several new $\mathrm{BC}$ drugs were approved by the FDA (eg, letrozole in 2001, fulvestrant in 2002, gemcitabine in 2004, nab-paclitaxel in 2005, lapatinib and ixabepilone in 2007), ${ }^{27}$ which may be available at branded price during the study period, thereby suggesting increased Medicare expenditures. ${ }^{28}$ In addition, use of more expensive radiation technology, such as brachytherapy and intensity-modulated RT, ${ }^{29}$ may also cause higher Medicare expenditures.

In contrast to the literature, ${ }^{4,10}$ our study found that physician services followed by outpatient services were the major contributors to the average total costs indicating an increased breast-conserving therapies ${ }^{30,31}$ and new adjuvant therapies that require more frequent monitoring as reflected by higher adjusted costs associated with surgery and/or adjuvant therapy in Table 3. These findings likely represent several changes in treatment patterns, including in-

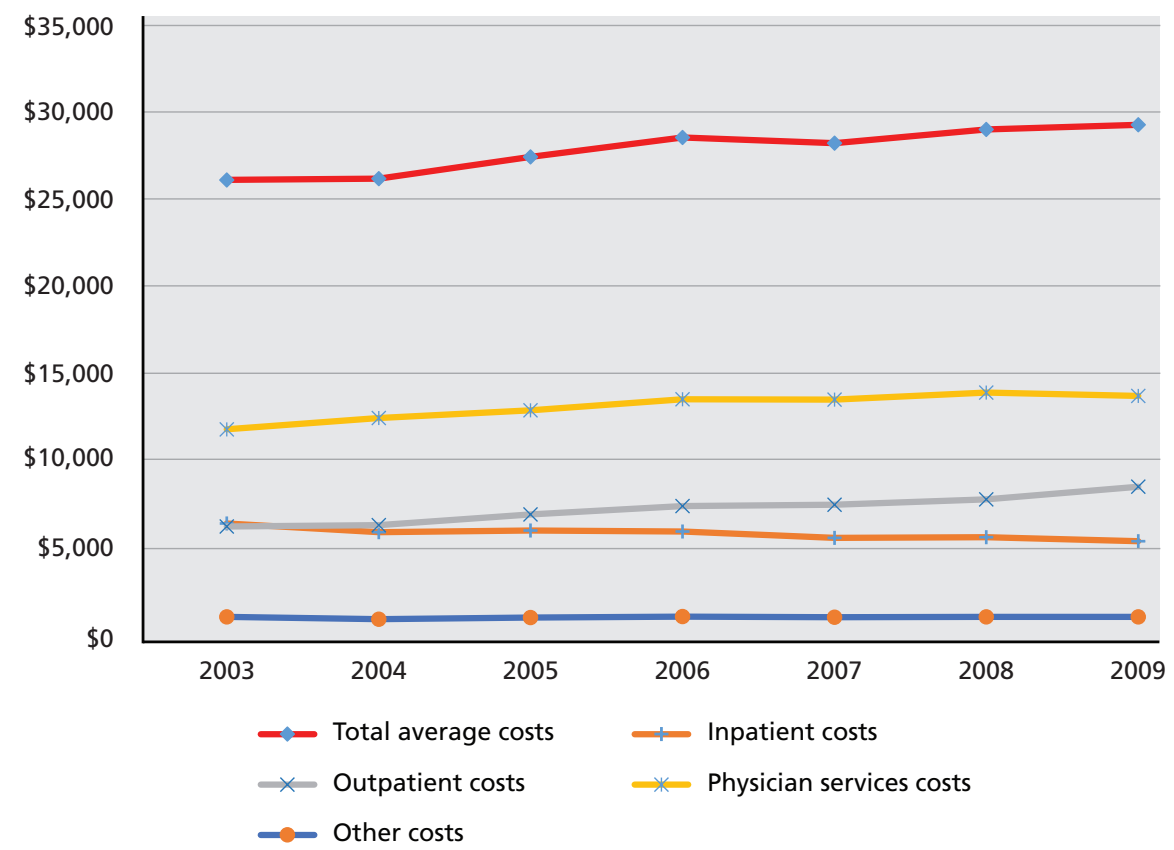

Figure 1. Trends in the average total costs and average costs by types of services during the initial phase of care among 69,307 elderly, female, SEERMedicare fee-for-service beneficiaries aged $\geq 66$ years diagnosed with first primary incident breast cancer from $2003-2009$. 
Healthcare Utilization and Costs in Breast Cancer

\begin{tabular}{|c|c|c|c|c|}
\hline Variables & Beta & $\begin{array}{c}\text { Average } \\
\text { Adjusted Costs, } \\
\text { \$USD }\end{array}$ & SE & Sig \\
\hline Intercept (baseline costs) & 8.8409 & $\$ 6,911$ & 0.0218 & * \\
\hline \multicolumn{5}{|l|}{ Age at diagnosis, y } \\
\hline \multicolumn{5}{|l|}{$66-69$} \\
\hline $70-74$ & -0.0437 & $\$ 6,616$ & 0.0064 & * \\
\hline $75-79$ & -0.0982 & $\$ 6,265$ & 0.0066 & * \\
\hline$\geq 80$ & -0.1540 & $\$ 5,925$ & 0.0067 & * \\
\hline \multicolumn{5}{|l|}{ Race } \\
\hline \multicolumn{5}{|l|}{ White } \\
\hline Black & 0.0363 & $\$ 7,167$ & 0.0091 & * \\
\hline Other & -0.0883 & $\$ 6,327$ & 0.0109 & * \\
\hline \multicolumn{5}{|l|}{ Location of residence } \\
\hline \multicolumn{5}{|l|}{ Metropolitan } \\
\hline Nonmetropolitan & -0.0555 & $\$ 6,538$ & 0.0077 & * \\
\hline \multicolumn{5}{|l|}{ Marital status } \\
\hline Married/Partnered & -0.0034 & $\$ 6,888$ & 0.0047 & \\
\hline \multicolumn{5}{|l|}{ Single/Divorced/Widowed } \\
\hline \multicolumn{5}{|l|}{ Census tract income } \\
\hline \multicolumn{5}{|l|}{$\leq \$ 25,000$} \\
\hline$\$ 25,001-\$ 50,000$ & 0.0138 & $\$ 7,007$ & 0.0096 & \\
\hline$\$ 50,001-\$ 75,000$ & 0.0455 & $\$ 7,233$ & 0.0111 & * \\
\hline$>\$ 75,000$ & 0.0765 & $\$ 7,461$ & 0.0130 & * \\
\hline \multicolumn{5}{|l|}{ Census tract education } \\
\hline \multicolumn{5}{|l|}{$0-13.33$} \\
\hline $13.34-22.98$ & 0.0093 & $\$ 6,976$ & 0.0066 & \\
\hline $22.99-38.79$ & 0.0080 & $\$ 6,967$ & 0.0073 & \\
\hline$\geq 38.80$ & -0.0067 & $\$ 6,865$ & 0.0087 & \\
\hline \multicolumn{5}{|l|}{ Stage at diagnosis } \\
\hline \multicolumn{5}{|l|}{ In situ } \\
\hline Localized & 0.1827 & $\$ 8,297$ & 0.0066 & * \\
\hline Regional & 0.4033 & $\$ 10,344$ & 0.0078 & * \\
\hline Distant & 0.7162 & $\$ 14,145$ & 0.0151 & * \\
\hline \multicolumn{5}{|l|}{ Tumor grade } \\
\hline \multicolumn{5}{|l|}{ Well-differentiated } \\
\hline Moderately differentiated & 0.0446 & $\$ 7,226$ & 0.0059 & * \\
\hline Poorly differentiated & 0.1155 & $\$ 7,757$ & 0.0069 & * \\
\hline Undifferentiated/Unknown & 0.0420 & $\$ 7,208$ & 0.0083 & * \\
\hline
\end{tabular}

Abbreviations: SE, standard error; Sig, significance.

${ }^{*} P<.001$ : statistically significant group differences based on generalized linear model with gamma distribution and log link function.

(continued)

creased costs of multimodal treatments ${ }^{29-33}$ and use of more expensive radiation technology, such as brachytherapy and intensity-modulated $\mathrm{RT},{ }^{29}$ which may have increased costs associated with physician and outpatient services. Moreover, it highlights the trend toward more patients with cancer receiving chemotherapy and RT in the outpatient clinic setting $^{34}$ than the inpatient setting. Furthermore, several drugs that were FDA-approved during our study period may require use of physician services for drug administration and hence lead to higher costs in this category. Finally, costs from inpatient services contributed significantly less to the average costs than reported in the literature, ${ }^{6,9,10}$ likely indicating the greater push by Medicare to decline inpatient status

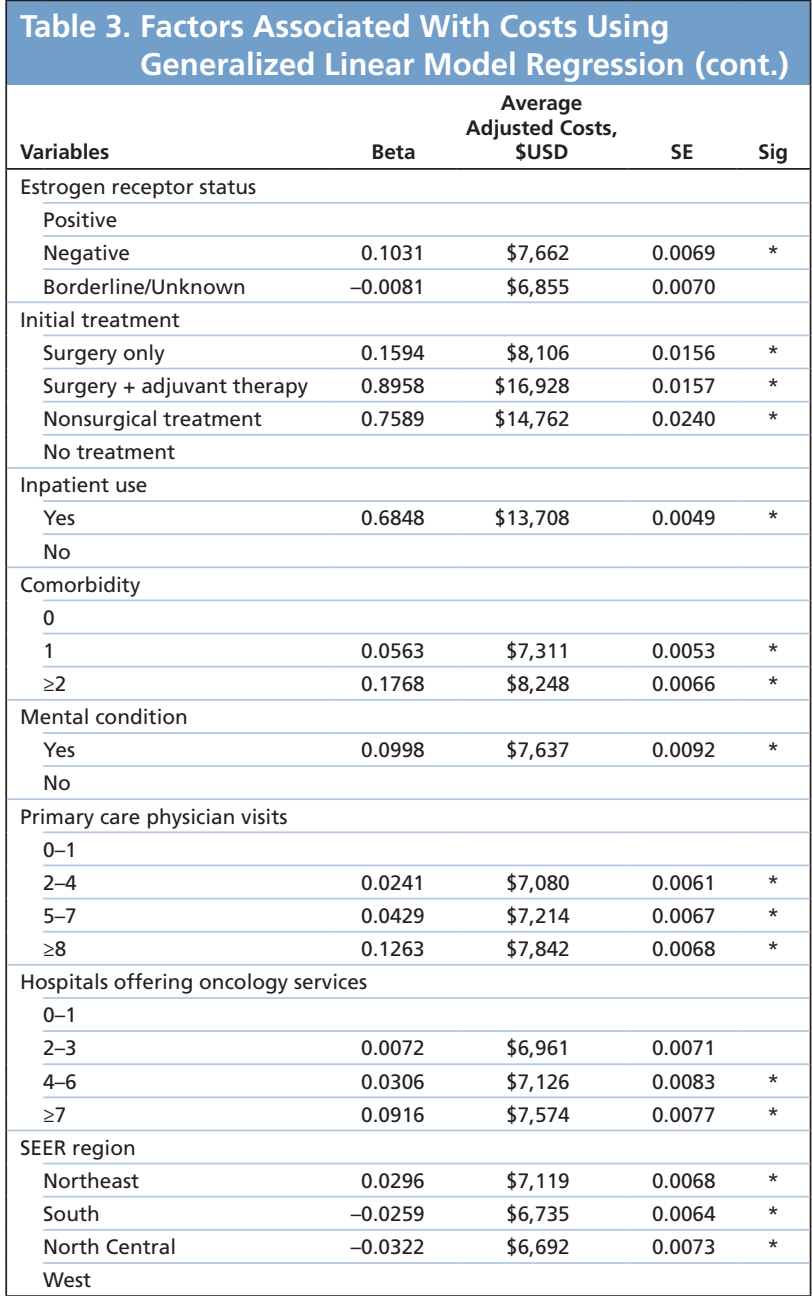

Abbreviations: SE, standard error; Sig, significance.

${ }^{*} P<.001$ : statistically significant group differences based on generalized linear model with gamma distribution and log link function.

and forcing observation care status for patients admitted after surgeries requiring hospital monitoring. This may also reflect a shift in Medicare reimbursement patterns. In addition, advancement in oncology and technology, varying demographics, and legislation may partly explain this shift. ${ }^{35}$ Future research exploring the newer adjuvant $\mathrm{BC}$ treatments should be conducted to identify the most cost-effective strategies to reduce treatment-related costs while improving health outcomes (eg, survival).

Among predisposing factors, age and race were significant predictors of cost. Increasing age at diagnosis resulted in decreasing costs, a similar finding as reported in published literature, ${ }^{5}$ perhaps because older women are less likely to receive aggressive 
Vyas et al

treatment after $\mathrm{BC}$ diagnosis, resulting in lower costs. ${ }^{16,36,37}$ Additionally, consistent with a previous study, ${ }^{5}$ higher costs were reported for African American women, perhaps because they have been shown to receive less preventive and diagnostic medical $\mathrm{care}^{38}$ and hence are more likely to use inpatient services, resulting in higher costs. ${ }^{39}$ Warren et $\mathrm{al}^{5}$ suggested that African American women may receive different treatment compared with white women, and that certain unmeasured factors (eg, body mass index, health status) may affect differences in care, thereby affecting costs. Among enabling factors, living in areas with higher household income was independently associated with higher costs, a similar finding as reported in a previous study. ${ }^{11}$

With regard to need-related factors, advanced disease stage, moderately and poorly differentiated tumor grade, ER-negative tumor status, and presence of chronic physical and mental conditions were significantly associated with higher costs. These findings are consistent with those of previous studies reporting significant increases in costs associated with advancing disease stages ${ }^{4,5,11,16}$ and the presence of comorbidities, ${ }^{11}$ suggesting the importance of comanagement of physical and mental chronic conditions $s^{40,41}$ and improving access to preventive cancer screening services for older women. Emerging healthcare delivery models, such as "medical homes," that emphasize care coordination for Medicare beneficiaries with multiple chronic conditions could be a step in the right direction to curb increasing costs associated with $\mathrm{BC}$ care. Among factors associated with healthcare use, women with $\mathrm{BC}$ who had surgery and adjuvant therapy and those who had nonsurgical treatment had higher costs than those who did not have any BC treatment, as reported by Penberthy et al. ${ }^{11}$ Furthermore, inpatient use and PCP visits were also significantly associated with higher costs. Older women with BC who resided in metropolitan areas and had access to a higher number of hospitals providing oncology services had higher costs in the initial phase of care, perhaps because of increased access to Medicare insurance.

Several limitations of this study are worth noting. Healthcare services not reimbursable by Medicare may not be captured, and healthcare utilization and costs of adjuvant therapy did not capture prescription drugs, potentially resulting in underestimation of cost. Data on variables such as health status, severity of comorbidities, and patient preferences, which may impact cancer prognosis and/or selection of $\mathrm{BC}$ treatment, were not available. Moreover, the study findings are generalizable to older patients with BC covered by Medicare.

\section{Conclusions}

This population-based study suggests that BC represents a substantial economic burden during the initial phase of care. Physician and outpatient services accounted for the highest proportion of costs. Predisposing factors, need-related factors, healthcare use, and external environmental healthcare-related factors significantly predicted costs.

\section{References}

1. Mariotto AB, Yabroff KR, Shao Y, et al. Projections of the cost of cancer care in the United States: 2010-2020. J Natl Cancer Inst 2011;103:117128.

2. Brown ML, Riley GF, Schussler N, Etzioni R. Estimating health care costs related to cancer treatment from SEER-Medicare data. Med Care 2002;40(8 Suppl):IV-104-117.

3. Campbell JD, Ramsey SD. The costs of treating breast cancer in the US: a synthesis of published evidence. Pharmacoeconomics 2009;27:199-209.

4. Riley GF, Potosky AL, Lubitz JD, Kessler LG. Medicare payments from diagnosis to death for elderly cancer patients by stage at diagnosis. Med Care 1995;33:828-841.

5. Warren JL, Brown ML, Fay MP, et al. Costs of treatment for elderly women with early-stage breast cancer in fee-for-service settings. J Clin Oncol 2002;20:307-316.

6. Yabroff KR, Lamont EB, Mariotto AB, et al. Cost of care for elderly cancer patients in the United States. J Natl Cancer Inst 2008;100:630-641.

7. Howlader N, Noone AM, Krapcho M, et al, eds. SEER Cancer Statistics Review, 1975-2013, National Cancer Institute. Bethesda, MD, based on November 2011 SEER data submission, April 2012. Available at: http:// seer.cancer.gov/csr/1975_2013/. Accessed January 21, 2017.
8. Yabroff KR, Warren JL, Brown M. Costs of cancer care in the USA: a descriptive review. Nat Clin Pract Oncol 2007;4:643-656.

9. Hanchate AD, Clough-Gorr KM, Ash AS, et al. Longitudinal patterns in survival, comorbidity, healthcare utilization and quality of care among older women following breast cancer diagnosis. J Gen Intern Med 2010;25:1045-1050.

10. Warren JL, Yabroff KR, Meekins A, et al. Evaluation of trends in the cost of initial cancer treatment. J Natl Cancer Inst 2008;100:888-897.

11. Penberthy L, Retchin SM, McDonald MK, et al. Predictors of Medicare costs in elderly beneficiaries with breast, colorectal, lung, or prostate cancer. Health Care Manag Sci 1999;2:149-160.

12. Warren JL, Klabunde CN, Schrag D, et al. Overview of the SEERMedicare data: content, research applications, and generalizability to the United States elderly population. Med Care 2002;40(8 Suppl):IV-3-18.

13. Engels EA, Pfeiffer RM, Ricker W, et al. Use of Surveillance, Epidemiology, and End Results-Medicare data to conduct case-control studies of cancer among the US elderly. Am J Epidemiol 2011;174:860-870.

14. National Cancer Institute, Division of Cancer Control \& Population Sciences. SEER-Medicare: About the Data Files. Available at: http:// healthcaredelivery.cancer.gov/seermedicare/aboutdata/. Accessed January 21, 2017

15. U.S. Health Resources and Services Administration. Bureau of Health Professions. Area Resource File, 2009-2010 Release. Rockville, MD: US 
Department of Health and Human Services; Fairfax, VA: Quality Resource Systems, Inc; 2010. Codebook: HE-001(2010).

16. Taplin SH, Barlow W, Urban N, et al. Stage, age, comorbidity, and direct costs of colon, prostate, and breast cancer care. J Natl Cancer Inst 1995;87:417-426.

17. Finkler SA. The distinction between cost and charges. Ann Intern Med 1982;96:102-109.

18. United States Department of Labor, Bureau of Labor Statistics. Consumer price index, medical care services, 1982-84. Available at: https:/www.bls. gov/cpi/. Accessed January 21, 2017.

19. Andersen R, Newman JF. Societal and individual determinants of medical care utilization in the United States. Milbank Mem Fund Q Health Soc 1973;51:95-124.

20. Andersen RM. Revisiting the behavioral model and access to medical care does it matter? J Health Soc Behav 1995;36:1-10

21. Young JL Jr, Roffers SD, Ries LA, et al, eds. SEER Summary Staging Manual - 2000: Codes and Coding Instructions, NIH Pub. No. 01-4969. Bethesda, MD: National Cancer Institute; 2001.

22. Klabunde CN, Potosky AL, Legler JM, Warren JL. Development of a comorbidity index using physician claims data. J Clin Epidemiol 2000;53:1258-1267.

23. National Cancer Institute, Division of Cancer Control \& Population Sciences. SEER-Medicare: Calculation of Comorbidity Weights. Available at: https://healthcaredelivery.cancer.gov/seermedicare/considerations/ calculation.html. Accessed January 21, 2017.

24. Yu X, McBean AM, Virnig BA. Physician visits, patient comorbidities, and mammography use among elderly colorectal cancer survivors. J Cancer Surviv $2007 ; 1: 275-282$

25. Manning WG. The logged dependent variable, heteroscedasticity, and the retransformation problem. J Health Econ 1998;17:283-295.

26. Manning WG, Mullahy J. Estimating log models: to transform or not to transform? J Health Econ 2001;20:461-494.

27. FDA Approved Drugs for Oncology: Drugs Approved in 2017. Available at: https://www.centerwatch.com/drug-information/fda-approved-drugs/ therapeutic-area/12/oncology. Accessed April 28, 2017.

28. Howard DH, Chernew ME, Abdelgawad T, et al. New anticancer drugs associated with large increases in costs and life expectancy. Health Affairs 2016;35:1581-1587
29. Roberts KB, Soulos PR, Herrin J, et al. The adoption of new adjuvant radiation therapy modalities among Medicare beneficiaries with breast cancer: clinical correlates and cost implications. Int J Radiat Oncol Biol Phy 2013;85:1186-1192.

30. Tuttle TM, Rueth NM, Abbott A, Virnig BA. Trends in the local treatment of breast cancer: should we be worried? J Surg Oncol 2011;103:313-316.

31. Yang RL, Newman AS, Lin IC, et al. Trends in immediate breast reconstruction across insurance groups after enactment of breast cancer legislation. Cancer 2013;119:2462-2468.

32. Kennedy T, Stewart AK, Bilimoria KY, et al. Treatment trends and factors associated with survival in T1aNO and T1bNO breast cancer patients. Ann Surg Oncol 2007;14:2918-2927.

33. Shih YC, Elting LS, Halpern MT. Factors associated with immunotherapy use among newly diagnosed cancer patients. Med Care 2009;47:948-958.

34. Halpern MT, Yabroff KR. Prevalence of outpatient cancer treatment in the United States: estimates from the Medical Expenditures Panel Survey (MEPS). Cancer Invest 2008;26:647-651.

35. Rubenstein EB. Costs and benefits of outpatient therapy. Support Care Cancer 1994;2:307-311.

36. Busch E, Kemeny M, Fremgen A, et al. Patterns of breast cancer care in the elderly. Cancer 1996;78:101-111.

37. Silliman RA, Troyan SL, Guadagnoli E, et al. The impact of age, marital status, and physician-patient interactions on the care of older women with breast carcinoma. Cancer 1997;80:1326-1334.

38. Escarce JJ, Epstein KR, Colby DC, et al. Racial differences in the elderly's use of medical procedures and diagnostic tests. Am J Public Health 1993;83:948-954.

39. Gornick ME, Eggers PW, Reilly TW, et al. Effects of race and income on mortality and use of services among Medicare beneficiaries. N Engl J Med 1996;335:791-799.

40. Subramanian S, Tangka FK, Sabatino SA, et al. Impact of chronic conditions on the cost of cancer care for Medicaid beneficiaries. Medicare Medicaid Res Rev 2013;2:pii: mmrr.002.04.a07.

41. Wodchis WP, Arthurs E, Khan AI, et al. Cost trajectories for cancer patients. Curr Oncol 2016;23(Suppl 1):S64-75. 